\title{
EXTRAFISCALIDADE COMO INSTRUMENTO DE IMPLEMENTAÇÃO DAS POLÍTICAS PÚBLICAS: ICMS ECOLÓGICO E IVA SOCIAL
}

\author{
EXTRAFISCALITY AS AN INSTRUMENT OF IMPLEMENTATION OF \\ PUBLIC POLICIES: ECOLOGICAL AND SOCIAL TAXES.
}

\author{
${ }^{1}$ Nina Gabriela Borges Costa \\ ${ }^{2}$ Allan Reymberg Souza Raulino
}

\section{RESUMO}

O presente trabalho visa realizar um estudo acerca da extrafiscalidade tributária como instrumento propiciador das políticas públicas, hoje vista como implementadora do desenvolvimento econômico, social e ambiental. Para comprovar tal premissa, estudar-se-á dois impostos que foram utilizados em sua função extrafiscal, para tentar corrigir e regular os problemas existentes em seus territórios, quais sejam: o Imposto sobre Circulação de Mercadorias e Serviços - Ecológico, um imposto brasileiro previsto na Constituição da República Federativa do Brasil, e o Imposto sobre o Valor Acrescentado Social, um imposto existente em alguns países Europeus que incide sobre as relações de consumo.

Palavra chave: Extrafiscalidade, políticas públicas, desenvolvimento.

\begin{abstract}
This work aims a study on the tax extrafiscality as a tool for providing public policies, which is seen as a trigger for the economic, social and environmental development. To prove such premise, it will be studied two taxes that were used for extrafiscal purposes in an attempt to correct and adjust the existing problems in their areas, which are: the tax on circulation and Ecological services, tax's Brazilian assured by the Federal Constitution of Brazil, and Social Value Added Tax, which is a tax that exists in some European countries as well whose focus is on the consumer relations.
\end{abstract}

Keywords: Extrafiscality; public policies; development

\footnotetext{
${ }^{1}$ Mestre em Direito Fiscal pela Faculdade de Direito da Universidade de Coimbra, FDUC - Coimbra, (Portugal). Professora e Coordenadora da Pós-Graduação da Faculdade Evolução do Alto Oeste Potiguar, FACEP-RN, (Brasil). E-mail: ninagabrielabc@gmail.com

${ }^{2}$ Mestre em Direito internacional Público pela Faculdade de Direito da Universidade de Coimbra, FDUC Coimbra, (Portugal). Professor da faculdade Evolução do Alto Oeste Potiguar, FACEP-RN, (Brasil). E-mail: aln_rey@hotmail.com
} 


\section{INTRODUÇÃO}

O presente trabalho visa à realização de um estudo acerca da extrafiscalidade da norma tributária como instrumento propiciador das políticas públicas, sendo esta vista como implementadora do desenvolvimento político, econômico, social e ambiental.

Tem-se, inicialmente, que o Estado Liberal foi marcado pela ideia de não intervenção do Estado na economia, possuindo o objetivo de assegurar os direitos individuais e não os direitos sociais e coletivos. Assim, como consequência de um Estado que pretendia ser econômico e socialmente mínimo, o tributo era visto unicamente com a finalidade fiscal, utilizado para manter o funcionamento da máquina administrativa.

Com a nova formação do Estado, bem como com a crise dos anos trinta, surge a necessidade de o ente estatal intervir nas relações privadas, a fim de promover políticas públicas em prol da promoção do bem-estar social. Finalidade essa denominada de extrafiscalidade da norma tributária, a qual tem por objetivo corrigir as externalidades positivas e negativas, ordenar ou reordenar a economia e as relações sociais, intervir no mercado, na redistribuição de riquezas, no planejamento familiar, nas questões ambientais, com o intuito de concretizar e alcançar o bem comum.

Diante disso, a fim de comprovar tal premissa, serão estudados, neste trabalho, dois impostos que foram utilizados em sua função extrafiscal, quais sejam: o Imposto Sobre Circulação de Mercadorias e Serviços Ecológico - ICMS Ecológico, um imposto brasileiro que se encontra previsto na Constituição da República Federativa do Brasil, bem como o Imposto sobre o Valor Acrescentado Social - IVA Social, um imposto incidente em alguns países Europeus, o qual recai sobre as relações de consumo.

Tratam-se de impostos completamente distintos, existentes em países completamente diferentes, com riquezas econômicas, sociais e naturais totalmente diversas, mas que se utilizaram da função extrafiscal para tentar corrigir e regular os problemas existentes em seus territórios.

Com isso, este trabalho será dividido em cinco capítulos. O primeiro capítulo tratará acerca da função social do tributo, levando em consideração a transição do Estado Liberal para Estado Social, momento em que o tributo passou a ser utilizado tanto como instrumento de intervenção na atividade econômica, como para propiciar serviços públicos, tais quais: saúde, educação, saneamento básico, entre outros. 
No segundo capítulo, será estudada a extrafiscalidade no que tange ao seu conceito, bem como sua importância e sua contribuição para a economia e para o meio ambiente.

No terceiro capítulo, analisar-se-ão os benefícios fiscais e a extrafiscalidade, uma vez que esta consiste em uma técnica de intervenção ou conformação social por meio da utilização dos tributos, os quais se dividem em impostos extrafiscais e benefícios fiscais, em que o primeiro tem por objetivo o desestímulo de determinadas atividades, por meio do agravamento da carga tributária, já o segundo tem por escopo o incentivo ou estímulo de certos comportamentos, pelo abrandamento da carga tributária ou até mesmo sua exclusão.

No quarto capítulo, estudar-se-á o ICMS Ecológico, o qual consiste no repasse de certa parcela do ICMS, arrecadado pelo Estado, aos municípios que possuem, em seus territórios, grande área de preservação ambiental, e, por isso, não se desenvolvem economicamente. Tal política foi criada no intuito de preservar o meio ambiente, bem como promover a igualdade financeira entre aqueles municípios pouco desenvolvidos. Entretanto, para fazer face ao recebimento de tal parcela, é exigida certa contraprestação por parte destes, como, por exemplo: investimento em educação, saúde, saneamento básico; variando de acordo com as exigências de cada Estado e as necessidades de cada município.

Por fim, na última parte do trabalho, será abordado o IVA Social, criado com o escopo de reduzir as contribuições sociais da conta das Entidades empregadoras, aumentando proporcionalmente a taxa do IVA, de modo que o financiamento da segurança social fosse, também, suportado pelos consumidores em geral. Assim, por meio desta política, as empresas se tornariam mais competitivas, diminuindo os incentivos para que elas se deslocassem para o exterior, gerando, consequentemente, o emprego e a renda aos locais onde fosse implantado tal sistema.

Diante de tudo que se pretende demonstrar no presente trabalho, cabe a seguinte indagação: É possível utilizar os tributos para resolver problemas sociais, políticos, econômicos e ambientais?

\section{A FUNÇÃO SOCIAL DO TRIBUTO}

O direito fiscal é um ramo do direito público que rege as relações jurídicas entre o Estado e os particulares, regulando as atividades financeiras do próprio Estado no que se refere à obtenção de receitas. Em outras palavras, o direito fiscal consiste em um conjunto de normas, as quais visam regular o comportamento das pessoas, a fim de levantar dinheiro aos 
cofres públicos, bem como regular os setores econômicos, sociais, políticos, ambientais, entre outros.

Antes de adentrar especificamente na função social do tributo, é mister destacar a evolução fiscal em que o conceito jurídico de tributo, bem como sua finalidade, se desenvolveu no contexto do Estado Liberal, e, sobretudo, do Estado Social, ao longo do tempo.

Tem-se, inicialmente, que, a partir do liberalismo político, surge o liberalismo econômico, marcado pelo pensamento do economista Adam Smith, o qual prega a separação entre sociedade e Estado, tendo como objetivo defender a sociedade do intervencionismo do Estado por meio da criação de algumas barreiras, haja vista entender a atuação estatal como um elemento embaraçador da ordem natural econômica, defendendo, ainda, o liberalismo individualista estabelecido a partir da mão invisível (NOVOA, 2012, pag. 100).

No ideal do Liberalismo, os direitos fundamentais do homem eram entendidos como direitos individuais e naturais anteriores ou superiores ao Estado. A esfera de atuação do Estado resumia-se, fundamentalmente, em assegurar a liberdade, a igualdade e a autonomia individual, o que se repercute numa visão marcadamente formalista do Direito e essencialmente protetora dos direitos individuais (PACHECO, 2011, pag. 44).

Com isso, tem-se o Estado Liberal marcadamente abstencionista, isto é, possuía por objetivo assegurar os direitos individuais, e não o escopo social, político ou econômico, pois estas eram prosseguidas pela atuação particular.

A concepção da época sobre direitos fundamentais e o império da lei refletiam no sistema financeiro, sustentado primordialmente por impostos, os quais se destinavam a manter um Estado que se pretendia ser mínimo, de modo a não perturbar a economia, ou seja, o princípio liberal veio atribuir ao imposto o papel de receita pública por excelência ${ }^{3}$.

Como consequência de um Estado econômico e socialmente mínimo, além de defensor da propriedade privada, os impostos da época não eram vistos como instrumento econômico e social, sendo os fins de sua criação unicamente fiscais, pois não perseguia preocupações econômicas ou sociais, como: a correção de mercado, a proteção do ambiente, o combate ao desemprego ou a redistribuição de riqueza (PACHECO, 2011, pag. 49).

\footnotetext{
${ }^{3}$ Pacheco (2011, pag. 47) estabelece, ainda, que, na ideia de estado liberal, apenas haveria bom orçamento aquele em que a parcela de riqueza retirada dos particulares correspondesse exatamente à parcela de receita indispensável para manter a máquina administrativa. Assim, a atividade financeira liberal é regida pelo principio do mínimo, em que há o setor público restrito e a tributação limitada.
} 
Nesse sentido também estabelece o Professor Doutor José Casalta Nabais (1994, pag. 194), ao dispor que o Estado liberal era movido pela preocupação de neutralidade econômica e social, em que visava buscar um Estado mínimo, assentado em uma tributação limitada, necessária para satisfazer as despesas estritamente decorrentes do funcionamento da máquina administrativa do Estado.

Todavia, a ideia de tributação com o intuito meramente arrecadatório, pelo qual o Estado visa captar recurso aos cofres públicos para se manter, encontra-se completamente ultrapassada por ter surgido a necessidade de o Estado intervir nas relações privadas no intuito de promover políticas sociais, econômicas e ambientais em prol da promoção do bem-estar social.

Assim, com os novos rumos econômicos e sociais, inseridos a uma ordem política e internacional, primordialmente a partir das grandes guerras, surgiram novas preocupações, e, em consequência disso, o Estado passa a ser chamado a intervir em determinadas situações a fim de criar uma política social que visava pôr fim ao liberalismo, visto que, de acordo com alguns estudiosos, a formulação de justiça tributária baseada unicamente na distribuição justa da carga tributária era a própria planta de uma ordem liberal a ser dada por vencida, pois o conceito de justiça fiscal passa a implicar o desaparecimento da ordem liberal, visando à assunção no interesse da intervenção pelo Estado sob o modelo de Estado Social (NOVOA, 2012, pag. 96).

Nesse sentido, paralelamente ao Estado fiscal clássico, surge a importância na identificação da extrafiscalidade fundamentalmente vinculada a existência de normas que possuam finalidades diferentes da simples arrecadação de fundos, servindo como instrumento de intervenção do Estado no Domínio Econômico e social (BONFIM, 2015. pag. 3).

De acordo com Professor Doutor José Casalta Nabais (1994, pag. 226), o melhor imposto já não é o imposto mínimo, equivalente, mas o que melhor se adapte aos objetivos das diversas funções do Estado.

Diante desses preceitos, têm-se que a tributação possui dupla finalidade, quais sejam: o papel de auferir recursos para que o Estado subsista e o papel de garantidor da realização dos direitos fundamentais dos cidadãos, os verdadeiros fins do Estado (MACHADO, 2008, Pag. 543).

Em virtude do que foi acima mencionado, percebe-se que, no Estado Democrático de Direito, a tributação passou a ser utilizada não apenas como ramo do Direito Tributário, mas também do Direito Econômico, como instrumento de intervenção do Estado na atividade 
econômica, na medida em que visa promover políticas de proteção do meio ambiente, a redistribuição de renda e de terra, a proteção à saúde, a defesa da economia, a redução das desigualdades, a busca pelo pleno emprego, entre outros.

\section{EXTRAFISCALIDADE}

Os tributos constituem instrumentos de arrecadação estatal para o custeio de despesas públicas, podendo ser utilizados, ainda, como instrumento interventivo na busca dos fins almejados (NABAIS, 1998, pag. 695). Este último objetivo é denominado extrafiscalidade tributária, pois a sua finalidade principal é interferir na economia privada, em setores econômicos, em regiões, estimulando ou desestimulando o consumo de certos bens, de determinadas atividades, entre outros.

Neste contexto, pode-se afirmar que a extrafiscalidade consiste na utilização do tributo como meio de fomento ou de desestímulo às atividades tidas como convenientes ou inconvenientes à comunidade, usados pelo governo na busca dos fins sociais, através da maior ou menor imposição tributária, uma vez que as diferentes onerações podem estimular ou desestimular condutas, visando sempre o interesse público.

A tributação extrafiscal caminha conjuntamente com o intervencionismo do Estado, na medida em que irá atuar sobre o mercado e sobre a livre iniciativa, sendo utilizada, também, para prevenção dos desequilíbrios de mercado e para o favorecimento da competitividade das empresas frente aos novos desafios globais (BASSO et all. 2012 pag. 19).

$\mathrm{Na}$ sua utilidade extrafiscal, tem-se a função arrecadatória inserida em segundo plano, visto que os tributos passam a atuar como auxiliares ao poder regulatório do Estado, permitindo a esse afastar, pelo agravamento da carga tributária, certas atividades ou comportamentos contrários a ordem pública, ou, por outro lado, estimular e incentivar pelo abrandamento da carga tributaria ou pelos benefícios tributários auferidos, os quais visam sempre atingir condutas convenientes (RAMALHO, 2013).

Ante ao exposto, verifica-se que a extrafiscalidade tributária se mostra como um instrumento extremamente importante para a tutela ambiental, ao permitir reduções de alíquotas, isenções ou afins, objetivando atingir as posturas ambientais corretas, bem como o desestímulo de condutas lesivas ou degradantes, por meio da oneração da carga tributária 
(RAMALHO, 2013), tema que atualmente tem apresentado inúmeros debates no cenário mundial.

Para o Estado atingir alguns de seus objetivos, mais especificamente atinente à preservação do meio ambiente, não é preciso instituir um novo tributo, mas sim utilizar os próprios tributos já existentes na sua função extrafiscal, aumentando ou reduzindo os impostos no intuito de atingir as metas almejadas, como, por exemplo, no caso do Imposto Sobre Circulação de Mercadorias e Serviços Ecológico - ICMS-E, um tributo estabelecido pela Constituição da República Federativa do Brasil, o qual sofreu reformulações nos seus critérios legais, visando à preservação do meio ambiente e o incremento da qualidade de vida da população.

Os tributos, na sua função extrafiscal, podem, ainda, ser utilizados para regular a economia, aumentando ou reduzindo a carga tributária, com o escopo de gerar reflexos na política internacional por meio da importação ou exportação de produtos, como, por exemplo, no Imposto Sobre o Valor Acrescentado Social - IVA Social, um imposto incidente em alguns países europeus, que tem por objetivo reduzir a carga tributária das contribuições sociais, compensando essa redução com o aumento proporcionado do IVA, de forma a aumentar a competitividade dos países que adotarem tal medida.

Diante disso, pode-se concluir que o Estado possui, em suas mãos, instrumentos hábeis, os quais possibilitam a ele se utilizar dos impostos na sua função extrafiscal, no intuito de regular e manipular comportamentos desejáveis, conforme se pode perceber a partir dos dois exemplos acima mencionados, sendo estes estudados de maneira mais aprofundada no decorrer desse trabalho.

\section{BENEFÍCIOS FISCAIS COMO POLÍTICA ECONOMICA E SOCIAL.}

É de se ressaltar que, de acordo com José Casalta Nabais (1998, pag. 630), a extrafiscalidade se expande em dois grandes elementos, cada um deles traduzindo uma técnica de intervenção ou conformação social por meio dos tributos, quais sejam: os impostos extrafiscais, bem como os benefícios fiscais. O primeiro é orientado para dissuasão ou evitação de determinados comportamentos por meio dos agravamentos extrafiscais. Já o segundo é dirigido ao fomento, incentivo ou estimulo de determinados comportamentos.

Os incentivos fiscais consistem em motivações criadas pelo Estado a fim de estimular certos setores e atividades tidas como de grande importância política, sendo uma 
das formas de utilização da política extrafiscal mais comuns, utilizando-se da redução da carga tributária a fim de induzir comportamentos, no intuito de que o Estado alcance os seus objetivos.

A extrafiscalidade passa, então, a ser identificada como o uso dos benefícios fiscais, tendo sido esta a forma de fomento econômico e redistribuição de riqueza feita dos desagravamentos com o que se entendia possível e desejável concretizar políticas econômicas e sociais (VASQUES, 2007, pag. 580).

Conforme se pode observar, a globalização não resolveu os problemas sociais e econômicos existentes no mundo atual, ao contrário, tem contribuído para aumentar ainda mais as diferenças entre os países desenvolvidos e aqueles em desenvolvimento, levando, muitas vezes, ao crescimento da pobreza e da exclusão social (BONELLA, 2016, pag. 13).

Para que o Estado alcance a realização de projetos políticos e de desenvolvimento, como geração de emprego, renda, distribuição de terra, proteção do mercado, da saúde e do meio ambiente, é preciso que existam fontes econômicas que promovam tais fins. E é por isso que a implementação de políticas tributárias, por meio de benefícios fiscais, deve visar o desenvolvimento local e a inclusão social, objetivos esses que passam a ser superiores à tão somente arrecadação fiscal.

De acordo com Bonfim (2015, pag. 93), a tributação, nesse contexto, é pensada como instrumento de atuação do Estado na difícil tarefa de equilibrar o desenvolvimento das diferentes regiões do país, de acordo com o que dispões o Artigo 43, § 2º III, CR/1988, além do artigo 151, I, CR/1988, o qual é categórico em permitir que a União estabeleça tratamento tributário não uniforme com o objetivo de reduzir as desigualdades regionais entre diferentes regiões do país ${ }^{4}$.

\section{A EXTRAFISCALIDADE DO IMPOSTO SOBRE CIRCULAÇÃO DE MERCADORIAS E SERVIÇOS ECOLÓGICO}

Como clara confirmação de tudo que já foi aqui exposto, temos a extrafiscalidade do Imposto Sobre Circulação de Mercadorias e Serviços - ICMS como um dos temas mais debatidos pelos tributaristas brasileiros, que o veem como um importante instrumento de

\footnotetext{
${ }^{4}$ Argumento também utilizado por Luiz Alberto Gurgel de Faria (2010), o qual menciona a previsão de que a lei orçamentaria plurianual estabeleça, de forma regionalizada, as diretrizes, os objetivos e as metas da Administração Pública Federal para as despesas de capital e outras delas decorrentes do artigo 165 CR/1988.
} 
política pública, utilizado com o objetivo de reduzir as desigualdades das sociedades e das economias pouco desenvolvidas e, por consequência, ajudar no processo de mudança social.

O Imposto Sobre Circulação de Mercadorias e Serviços encontra-se previsto na Constituição da República Federativa do Brasil, em seu artigo 155, inciso II, e disciplinado pela Lei Complementar $n^{\circ}$ 87, de 13 de setembro de 1996, sendo uma das principais fontes de arrecadação dos Estados brasileiros. A este tributo é permitida a repartição de receitas, de modo que $25 \%$ da sua arrecadação seja repassada aos municípios, conforme artigo 158, VI da Constituição da República.

Assim, por meio da tributação extrafiscal, vários Estados Brasileiros vêm empregando certa parcela da repartição tributária do ICMS às ações direcionadas a benefícios dos municípios, uma vez que a repartição tributária possibilita o acréscimo de suas verbas, com base em critérios sociais que irão refletir na qualidade de vida da sociedade, sendo, também, a possibilidade de o Estado interferir no processo de desenvolvimento de seus municípios, ao premiar certas atividades e limitar outras (PORTELA, 2016).

Dentro dessa ideia de repartição de receitas, e buscando a ideia de justiça social e desenvolvimento sustentável, surge o ICMS - Ecológico, o qual foi criado no intuito de beneficiar os municípios que possuem, em seus territórios, grande área de preservação ambiental, conforme se segue.

$\mathrm{Na}$ contemporaneidade, as questões ambientais se tornaram centro de preocupações mundiais, sendo classificadas como direitos de terceira geração e consideradas de maior importância (COUTINHO, 1992, p.43). Nesta perspectiva, a Constituição da República Federativa do Brasil de 1988, nos seus artigos 225 e 170, inciso VI, consagra o direito ao meio ambiente equilibrado, como um direito fundamental de todos, e, além do mais, ressalta a importância da compatibilização entre o desenvolvimento econômico e a preservação do meio ambiente, buscando um equilíbrio entre ambos.

Neste contexto, é pertinente resaltar a importância de aproximar crescimento e desenvolvimento econômico com a preservação do meio ambiente, pois "a natureza é a base necessária e indispensável da economia moderna, bem como da vida das gerações presentes e futuras" (BINSWANGER, 1999, p. 51), e, para atingir esse objetivo, o Estado, amparado pelo artigo 174 da Constituição da República, ao usar da intervenção indireta, por meio de instrumentos econômicos de indução, traz a tona a extrafiscalidade tributária, com o escopo de estimular a proteção do meio ambiente, retirando do tributo o caráter unicamente arrecadatório e lhe atribuindo a função de intervenção no meio social. 
Conforme já mencionado, em alguns Estados brasileiros, a intervenção no meio ambiente vem ocorrendo por meio do ICMS - Ecológico, em que, dos 25\% da parcela repassada aos municípios, certa percentagem é repassada exclusivamente a municípios, mediante o cumprimento de algumas exigências, as quais envolvem preservação ambiental, saneamento básico, investimentos em saúde, educação, entre outros.

O ICMS Ecológico surgiu, inicialmente, com o objetivo de compensação, pois pretendia ser um instrumento de recompensa aos municípios que possuíam, nos seus territórios, grandes áreas de preservação ambiental constituídas por unidades de conservação de mananciais de abastecimento de água, vistas como um bloqueio ao desenvolvimento econômico, mas que, ao mesmo tempo, eram responsáveis pelo abastecimento de água, atendendo vários outros municípios mais desenvolvidos (MURER, 2010, pag. 197). Portanto, tendo em vista o seu desenvolvimento econômico encontrar-se comprometido, o fato de a proteção ambiental envolver custos elevados, e este sacrifício beneficiar outros municípios, nada mais justo do que a adoção de critérios que compensem esta restrição, com o repasse de verbas para estes municípios (VIDONHO. 2007. pag. 199).

Contudo, a função compensatória acabou sendo substituída por uma consequência incrementadora, pois grande parte dos municípios passaram a implementar políticas ambientais de preservação, visando receber uma parcela dos valores distribuídos.

O ICMS Ecológico passou a objetivar duas funções: compensatória e indutiva. A primeira diz respeito à promoção da igualdade econômica entre os vários municípios de um Ente Federado, retribuindo àqueles municípios financeiramente menos desenvolvidos devido à extensa área de preservação ambiental. Já a segunda, busca fazer com que os municípios, mediante a promessa de incremento da receita tributária, realizem políticas públicas para conservar o meio ambiente, o saneamento ambiental, o desenvolvimento sustentável e a melhora dos indicadores sociais (RAMALHO, 2016, pag. 9).

O Estado do Paraná foi o primeiro Estado brasileiro a implantar o ICMS Ecológico e

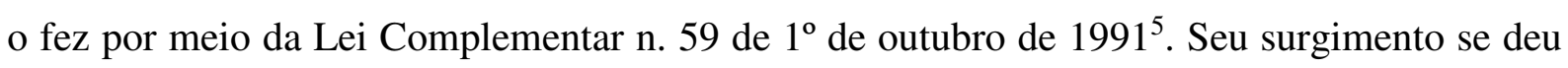

\footnotetext{
${ }^{5}$ A Lei complementar 59/1991 dispõe que 5\% da repartição do ICMS será repassado aos municípios com mananciais de abastecimento e unidades de conservação ambiental:

Art. $4^{\circ}$. A repartição de cinco por cento (5\%) do ICMS a que alude o artigo $2^{\circ}$ da Lei Estadual no 9491 , de 21 de dezembro de 1990, será feita da seguinte maneira:

- cinquenta por cento (50\%) para municípios com mananciais de abastecimento.

- cinquenta por cento $(50 \%)$ para municípios com unidades de conservação ambiental.

Parágrafo único. No caso de municípios com sobreposição de áreas com mananciais de abastecimento e unidades de conservação ambiental, será considerado o critério de maior compensação financeira.
} 
por iniciativa dos próprios municípios, que se encontravam em dificuldades financeiras por possuírem grandes áreas de conservação ambiental e nascentes de águas que abasteciam outros municípios, servindo de exemplo para vários outros Estados.

Hodiernamente, o ICMS Ecológico é realidade em outros Estados da Federação, como é o caso de São Paulo, Minas Gerais, Amapá, Rondônia, Rio Grande do Sul, Pernambuco, Tocantins, Goiás e Rio de janeiro (RAMALHO, 2016, pag. 9), que criaram legislações próprias, com critérios ambientais para repasse do ICMS aos municípios.

São Paulo foi o segundo Estado a implantar tal medida em seu território, seguido por Minas Gerais, que o fez por meio da Lei Estadual n 12.040/95 de 28 de dezembro de 1995, denominada "Lei Robin Hood", retirando a arrecadação dos municípios economicamente mais desenvolvidos para favorecer os municípios mais pobres. Tal medida foi criada por iniciativa do governo estadual, com o objetivo de fazer justiça social, de atenuar os graves desequilíbrios regionais, por meio de uma distribuição socialmente mais justa, que incentivasse o investimento em áreas prioritárias, como, por exemplo, educação, saúde, agricultura, patrimônio cultural e preservação ambiental.

A Legislação mineira inovou ao apresentar novos critérios de partilha do ICMS, sendo considerada uma das mais modernas Legislações. A referida Lei dividiu o repasse do imposto em ICMS Verde, o qual leva em consideração as áreas preservadas; e ICMS Marrom, o qual leva em consideração o tratamento de esgoto e de resíduos sólidos.

Portanto, cada Estado reformula os critérios para o repasse do ICMS como melhor lhe convier (RAMALHO, 2016, pag. 8), visto que o ICMS Ecológico passa a ser estabelecido em razão das prioridades de cada Estado da Federação.

Sendo assim, vários autores irão afirmar que a política do ICMS Ecológico irá representar uma brilhante intervenção positiva do Estado, uma vez que atua dando auxílios, tais como incentivos fiscais intergovernamentais, representando um instrumento econômico de uma política pública que surte efeito extrafiscal com vistas à consecução de uma finalidade constitucional de preservação, promovendo a justiça fiscal, atuando e conduzindo a ação voluntária dos municípios que buscam um aumento de receita e uma qualidade de vida para toda a sociedade (MURER, 2005, pag. 194).

O ICMS Ecológico tem alcançado resultados significativamente positivos, isso porque tem alcançado objetivos que, até então, diversas medidas mitigatórias de proteção ambiental não haviam conseguido. Todas as medidas utilizadas pelo Estado, a fim de intervir no domínio econômico, se revelavam frágeis, não produzindo os resultados ambientais 
desejados (RAMALHO, 2016, pag. 10). A partir de então, se faz necessário a utilização de medidas que visem trocar o caráter proibitivo e sancionatório por estímulos e incentivos capazes de alcançar os objetivos almejados para defesa do meio ambiente.

Com isso, o ICMS Ecológico se mostra como legítimo representante dos instrumentos de indução, por meio da sua extrafiscalidade, realizando o ideal de desenvolvimento sustentável, albergado pela Constituição da República, visto que busca desvincular a preservação ambiental da carga negativa que possui, se transformando em mais do que uma necessidade, mas em um desejo dos municípios que anseiam por crescimento econômico.

Cabe ressaltar, ainda, que o ICMS Ecológico visa dar consecução a outros princípios de ordem econômica, constantes na Constituição da República em seu artigo 170, VII, que estabelece acerca da redução das desigualdades regionais e sociais, pois justamente os municípios mais pobres são os mais beneficiados com o ICMS Ecológico, pelo fato de possuírem maiores áreas de preservação ambiental, e, consequentemente, menor atividade econômica.

A valorização do meio ambiente por meio de incentivos fiscais faz com que os municípios preservem seus ecossistemas não somente pelas contribuições ambientais que geram benefícios ao bem-estar e à saúde, mas pelo caráter econômico e do estímulo à manutenção das áreas ambientais (REIS, 2011, pag. 110).

Diante de todo o exposto, trata-se de uma política tributária eficiente e apta à função que lhe foi dada, sendo um importante instrumento de política ambiental por meio da extrafiscalidade, pois a função preventiva aliada ao instrumento econômico vem apresentando resultados satisfatórios em diversos Estados, sendo importante, ainda, para resolver problemas econômicos e sociais, como no caso do IVA social, que estudaremos a seguir.

\section{IMPOSTO SOBRE O VALOR ACRESCENTADO SOCIAL - IVA SOCIAL.}

O Imposto Sobre o Valor Acrescentado - IVA é um imposto geral sobre o consumo em que se tributam as transmissões de bens, a prestação de serviços, as importações e a aquisição intercomunitária de bens (NABAIS, 2010, pag. 617). 
Em sede de tributação do Imposto sobre o Valor Acrescentado encontra-se o IVA social, o qual possui como escopo interferir na economia de forma a aumentar a competitividade do país que adote tal medida.

O IVA Social consiste basicamente no aumento da taxa do Imposto sobre o Valor Acrescentado - IVA, e uma proporcional redução dos encargos relativos ao financiamento da proteção social, objetivando reduzir os custos com os trabalhadores, sem que tal redução interfira nos salários destes.

Em outras palavras, o IVA Social consiste na diminuição das contribuições sociais por parte das entidades empregadoras, com o objetivo de abaixar os custos de produção, contribuindo para que as empresas se tornem mais competitivas e menos propensas a se deslocarem para outros mercados. A neutralidade do ponto de vista das receitas públicas é alcançada por meio do aumento proporcionado, através de uma elevação da taxa do IVA (LIMA, 2012, pag. 89).

É importante estabelecer que o IVA Social não visa trazer benefícios para a classe dos trabalhadores, mas para toda sociedade, pois os benefícios gerados por esse instituto fazem com que, consequentemente, a empresa permaneça no local, o que traz diversos benefícios para a sociedade, como, por exemplo, a geração de emprego, renda, aumentando, também, a capacidade de consumo da população em geral.

Com isso, deve-se ressaltar que, se há um impacto positivo sobre o mercado de trabalho, alguns trabalhadores desempregados iriam encontrar empregos e a massa salarial aumentaria, o que significa que o impacto depressivo sobre o consumo, muitas vezes citado pelos opositores desta medida, só seria menor ou mesmo inexistente (CACHEUX, 2016).

O objetivo desse imposto consiste, ainda, em repassar para a sociedade consumidora o financiamento da seguridade social, de forma que essa também participe ativamente do financiamento das despesas sociais, com o intuito de que os encargos com a segurança social deixem de penalizar apenas o trabalho e o capital (LIMA, 2012, pag. 89).

É importante destacar, também, que não se trata da criação de um novo imposto, mas apenas a reacomodação do mesmo, para que este atinja a sua política extrafiscal, de forma a corrigir os problemas econômicos e sociais existentes no território Europeu.

O IVA Social permite atenuar o impacto negativo da atual sobrevalorização do euro nas exportações e tem o mesmo efeito prático que se deseja com a desvalorização monetária, a qual não é permitida entre os paises pertencentes à União Europeia, dado o fato de existir uma moeda única. Quanto aos produtos, espera-se que o acréscimo da taxa do IVA seja 
compensado no seu efeito sobre os preços finais, haja vista esperar que o decréscimo ou a eliminação das contribuições diretas para a segurança social tragam consequências na redução dos custos de produção e, consequentemente, nos preços dos produtos (VALADA, 2007).

Assim, a motivação para que ocorra um aumento no IVA tem como fundamento a recente necessidade de crescimento da competitividade internacioal. A transferência da carga fiscal do trabalho para o consumo levaria a uma redução dos custos de produção do trabalho, o que reduziria, consequentemente, os preços dos produtos e melhoraria a demanda de trabalho, enquanto o aumento do IVA aumentaria os preços de importação, sem influência sobre as exportações (NABAIS, 1998, pag. 688), induzindo a uma aparente queda nos preços de exportação. Finalmente, a reforma tenderia a estimular o crescimento da competitividade e do emprego (REBIERE, 2013).

Tal medida tem sido vista por muitos países como uma política global, a qual favorece a competitividade do país que a adote, uma vez que o custo do trabalho tem sido um elemento decisivo na economia do país, vindo a constituir um dos fatores de concorrência (LIMA, 2012, pag. 89 e ss).

O IVA Social foi implantado pela primeira vez na França, em que, para pôr fim à greve geral de 1968, o governo Francês promoveu um forte aumento do salário mínimo nacional. Com isso, haveria a necessidade de se buscar a desvalorização do franco Francês para equilibrar a economia. Entretanto, o governo optou pela adoção de outra medida, qual seja: o IVA Social, o qual se traduziu em suprir as contribuições sociais em sete milhões de francos, compensando esta perda de receita com o aumento de $2,5 \%$ da taxa normal do IVA. Tal medida foi neutra, os custos das empresas abaixaram, os produtos exportados viram o seu preço diminuir e as exportações aumentaram. Em contrapartida, os produtos importados não se beneficiaram da baixa dos custos e enfrentaram IVA mais elevado nas fronteiras, tornando os produtos mais caros do que os produzidos internamente (LIMA, 2012, pag. 92).

A partir de então, vários outros países europeus passaram a implantar tal medida em seus territórios, tendo resultados significativamente satisfatórios em relação à competitividade, tais como: Dinamarca, Alemanha, Hungria, Martinica e Guadalupe.

A implantação do IVA Social na Dinamarca ocorreu no período de 1987, em que a eliminação das contribuições sociais da carga das empresas foi compensada pela elevação de $2 \%$ no valor da taxa normal do IVA. Estudos apontam que não houve inflação, as empresas preservaram a competitividade e reduziram significativamente a taxa de desemprego. Já na 
Alemanha, tal medida foi implantada em 2007, apresentando uma compensação na redução da contribuição social de 3\%, elevando a taxa do IVA de $16 \%$ a $19 \%$. Esta medida contribuiu para o aumento do PIB em 3\%. A Hungria adotou o IVA Social em 2009, quando o governo aumentou o IVA de $20 \%$ para $25 \%$ e reduziu os preços das empresas de $32 \%$ para $27 \%$ (REBIERE, 2013, pag. 4). Outros Estados ultramarinos franceses, Martinica e Guadalupe, também adotaram esta política, aumentando em $2 \%$ a taxa normal do IVA, e isentando, consequentemente, as contribuições sociais nas áreas de indústria, imprensa, hotelaria, agricultura e pesca. Uma pesquisa realizada em 1999 apontou que a geração de emprego nas áreas de isenção quadruplicou em relação às não isentas, tendo efeitos positivos para estes territórios (LIMA, 2012, pags. 93 e 97).

O IVA Social apresenta uma série de vantagens que podem ser percebidas por diversas formas: as exportações tornam-se mais competitivas, tendendo a crescer, uma vez que se beneficiam da diminuição dos custos de produção, além da isenção do IVA em obediência ao princípio de tributação no país de destino. Por outro lado, diminuem as importações, sendo esse, também, um dos objetivos do IVA Social, a fim de melhorar a balança comercial a curto prazo; as empresas nacionais ficam mais competitivas, suportando custos de produção mais baixos; há a contribuição para o desincentivo das empresas em se deslocarem para o estrangeiro; e o emprego tende a aumentar, visto que ficam facilitadas novas contratações de trabalhadores (LIMA, 2012, pag. 90).

Segundo estudos, os países que aderiram a esse instituto demonstraram taxas de crescimento superiores aos demais países da União Europeia e taxas de desemprego muito inferiores.

Assim, como não é possível a desvalorização econômica, dado o fato de, na Europa, existir a utilização de uma moeda única, tal objetivo pode ser facilmente substituído pela possibilidade da utilização da extrafiscalidade tributária, a qual irá permitir estratégias e medidas de caráter fiscal para resultar no realinhamento da taxa de câmbio (LIMA, 2012, pag. 94). Com isso, tal medida tem sido adotada por vários países e aconselhada por vários estudiosos para fazer face aos desafios e resolver os problemas com que, hodiernamente, se tem defrontado alguns países da Europa.

\section{CONCLUSÃO}


O presente trabalho teve por objetivo realizar um estudo sobre a extrafiscalidade da norma tributária como instrumento propiciador das políticas públicas, devendo ser utilizada pelo poder estatal no intuito de interferir nas relações privadas, a fim de promover políticas sociais e ambientais em prol da promoção do bem-estar social.

Neste contexto, a extrafiscalidade da norma tributária passa a atuar conjuntamente com o intervencionismo do Estado, na medida em que visa regular comportamentos no sentido de controlar a economia, redistribuir riquezas, prevenir desequilíbrios de mercado, preservar o meio ambiente, contribuir para a competitividade das empresas diante dos novos desafios globais, entre outros.

Com isso, foi realizado um estudo sobre dois impostos extrafiscais, um existente no Brasil e o outro utilizado em alguns países da Europa: o ICMS Ecológico e o IVA - Social. Ambos os impostos foram utilizados em sua política extrafiscal a fim de corrigir e manipular comportamentos em prol dos benefícios coletivos.

O primeiro foi utilizado a fim de preservar e propiciar um meio ambiente equilibrado e igualar a condição social daqueles municípios que, por possuir áreas de preservação ambiental, se encontravam limitados no exercício de suas atividades econômicas, e, por isso, se encontravam em situações economicamente inferiores em relação aos demais municípios.

Já no segundo imposto, foi utilizada uma política fiscal de modo a compatibilizar a redução em relação a gastos tributários com a seguridade social por parte das entidades empregadoras, com um proporcional aumento do Imposto Sobre o Valor Acrescentado. Tal medida visava alcançar resultados produzidos com a desvalorização monetária, em que há a redução da mão de obra e, consequentemente, a baixa nos preços dos produtos, o que favorecia para a exportação, e, com o aumento do IVA, barraria a importação, que enfrentaria impostos mais altos nas fronteiras, trazendo, assim, competitividade para as empresas, reduzindo, ainda, o incentivo de elas se deslocarem para o exterior. Assim, como não é possível a desvalorização econômica na Europa, por existir uma moeda única, tal objetivo poderia ser facilmente substituído pela possibilidade da extrafiscalidade, a qual permitiria estratégias e medidas de caráter fiscal para resultar no realinhamento da taxa de câmbio nos países que adotassem tal medida.

Conforme foi comprovado, os dois impostos estudados atenderam satisfatoriamente aos objetivos pelos quais foram criados, sendo copiados e aconselhados por vários estudiosos para fazer face aos desafios com que atualmente se tem defrontado vários Estados, a fim de 
alcançar os fins sociais de proteção ambiental, no caso do ICMS Ecológico, e desenvolvimento econômico e social, no caso do IVA Social.

Com isso, conclui-se que a tributação por meio da extrafiscalidade constitui um importante instrumento da sociedade para promover políticas públicas a fim de resolver problemas ambientais, problemas em relação à redistribuição de renda e de terra, a proteção da saúde, a redução de desigualdades, a busca pelo pleno emprego, problemas sociais, econômicos e financeiros, sendo capaz, ainda, de amenizar os reflexos advindos de crises econômicas e financeiras enfrentadas por vários países, podendo trazer resultados significativamente positivos para o Estado, bem como para a economia do país, visto que acaba por gerar benefícios superiores ao objetivo meramente arrecadatório, na medida em que visa assegurar os direitos fundamentais a que se propõe dentro de um Estado Social.

\section{REFERÊNCIAS BIBLIOGRÁFICAS}

AMARAL, Paulo Adyr Dias do. A Extrafiscalidade ambiental e desenvolvimento sustentável. Paulo Adyr Dias do Amaral; Luiz Gustavo Levante (Orgs) Belo Horizonte: Edtora D’ Plácido, 2014.

ATALIBA, Geraldo. IPTU: progressividade. Revista de Direito Público. v. 23, n.93, jan./mar,1990.p.233.

BASSO, Ana Paula, SANTOS, Rodrigo Lucas C. CONCORRÊNCIA E DESENVOLVIENTO: CONTRIBUTO DA EXTRAFISCALIDADE DA TRIBUTAÇÃO. Revista Direito e Desenvolvimento, a. 3, n. 5, janeiro/junho 2012, p. 15.

BALEEIRO. Aliomar (1905-1978) Limitações ao Poder de Tributar/Aliomar Baleeiro - $8^{\text {a }}$ ed. atualizado por Misabel Abreu Machado Derzi. Rio de Janeiro: Forense, 2010.

BRASIL. Constituição (1988) Constituição da República Federativa do Brasil. Brasília: Senado, 1988.

BINSWANGER, Hans Chirstoph. Fazendo a sustentabilidade funcionar. In: CAVALCANTI, Clóvis (Coord), Meio Ambiente, desenvolvimento sustentável e políticas públicas. São Paulo: Cortez; Recife: Joaquim Nabuco, 1999,

BOBBIO, Norberto. Trad. de Carlos Nelson Coutinho. A Era dos Direitos. Rio de Janeiro: Campus, 1992.

BONELLA. Danielle Soncini, RODEMBUSCH.Claudine Freire. ANÁLISE DA EXTRAFISCALIDADE TRIBUTÁRIA COMO FORMA DE IMPLEMENTAÇÃO DE POLÍTICAS PÚBLICAS DE DESENVOLVIMENTO LOCAL E INCLUSÃO SOCIAL. Disponível 
http://www.domalberto.edu.br/gradu/Producao_docente/CLAUDINE/VI\%20Semin\%E1rio\% 20Internacional\%20UNISC.pdf. Acesso em: 07 de agosto de 2016.

BONFIM, Diego. Extrafiscalidade: identificação, fundamentação, limitação e controle/ Diego Bonfim. - 1. Ed - São Paulo: Noeses, 2015. 394.

CACHEUX. Jacques Le. "Social VAT": Is it anti-social? January 9th, 2012, disponível em: http://www.ofce.sciences-po.fr/blog/?p=999, acesso em 01 de junho de 2016.

COELHO, Sacha Calmon Navarro. Curso de Direito Tributário Brasileiro. 9 ed. rev. e atual, rio de janeiro: forense, 2008, 917p.

FARIA, Luiz alberto Gurgel. A EXTRAFISCALIDADE E A CONCRETIZAÇÃO DO PRINCÍPIO DA REDUÇÃO DAS DESIGUALDADES REGIONAIS. São Paulo: Quartier Latin, 2010.

FERREIRA, Manoel Gonçalves Filho. Direitos Humanos Fundamentais. 4. ed. São Paulo: Saraiva, 2000.

GONZALEZ. Luis Manuel Alonso. Los impuestos autonômicos de caracter extrafiscal. Madrid : Marcial Pons, 1995. 136 p.

GOUVÊA, Marcus de Freitas. A extrafiscalidade no direito tributário. Belo Horizonte: Del Rey, 2006. 298p.

LIMA. Emanuel Vidal. IVA social ou IVA anti-deslocalização/ Emanuel Vidal Lima. Revista de Finanças Públicas e Direito Fiscal. A. 5, nº 3 (2012), p. 87-109.

MACHADO, Hugo de Brito. Curso de direito tributário. 29. ed. rev., atual. e ampl. São Paulo: Malheiros, 2008. 543 p.

MURER, Yully Cristiano, OLIVEIRA. Thiago Vieira Mathias de Oliveira. O ICMS ECOLÓGICO E A IMPLEMENTAÇÃO DE POLÍTICAS PÚBLICAS AMBIENTAIS NO ESTADO DE RONDÔNIA. Revista de Direito Público, Londrina, V. 5, n.1 2010, pag. 185-216.

MINAS GERAIS. ICMS ECOLÓGICO. HISTÓRICO E PERSPECTIVAS. Disponível em http://www.icmsecologico.org.br/index.php?option=com_content\&view=article\&id=72\&Item $\underline{\mathrm{id}=77}$, acesso em 09 de junho de 2016.

MINAS GERAIS. Lei Estadual no 12.040/95 de 28 de dezembro de 1995. Diário do executivo do Estado de Minas Gerais. Belo Horizonte/MG. Pub. 29/12/1995.

NABAIS, José Cassalta. O dever fundamental de pagar impostos. Coimbra: Liv Almedina, 1998

NABAIS. José Casalta. DIREITO FISCAL. 6ªD. Editora: Coimbra. 2010. 687 pag. 
NABAIS. José Casalta. Contratos Fiscais: reflexões acerca da sua admissibilidade. Coimbra: Coimbra Editora, 1994.

NOVOA. Cesár Garcia. EL CONCEPTO DE TRIBUTO. 1 a Ed. - Buenos Aires: Marcial Pons Argentina. 2012. 352 p.

PARANÁ. Lei 59 de $1^{0}$ de outubro de 1991. Curitiba/PR: Palácio do Diário Oficial, 1991.

PACHECO, Ana Sophia Assis. DOS IMPOSTOS FISCAIS AOS IMPOSTOS EXTRAFISCAIS. DO ESTADO LIBERAL AO ESTADO SOCIAL. Da Extrafiscalidade. Coordenação: Manuel Pires. Lisboa. 2011.

PEREIRA. Paulo Trigo. Economia e finanças públicas: da teoria à prática. $3^{\mathrm{a}}$ Ed: Almedina. 303 p.

PORTELA. Paulo Henrique Gonçalves, BELCHIOR, Germana Parente Neiva. O ICMS COMO INSTRUMENTO DE DIREÇÃO SOCIAL. Artigo publicado pelo Comped. Disponível em: http://www.conpedi.org.br/manaus/arquivos/anais/bh/germana_parente_neiva_belchior2.pdf, acesso em 01 de junho de 2016.

RAMALHO, Leila Von Söhsten; PASSOS, Rosana Maciel Bittencourt. A EFICÁCIA DO OCMS ECOLÓGICO COMO INSTRUMENTO DE POLÍTICA AMBIENTAL E O DEVER DO ESTADO QUANTO A SUA EFETIVAÇÃO. Artigo publicado na Revista da Procuradoria Geral do Estado da Bahia. Disponível em: http://www.pge.ba.gov.br/Images/upload/File/Artigos/2010/ROSANA\%20MACIEL\%20BIT TENCOURT\%20PASSOS\%20E\%20LEILA\%20VON\%20S\%C3\%96HSTEN\%20RAMALH O/Leila_von_Sohsten_Ramalho_e_Rosana_Maciel_Bittencourt_Passos\%5B1\%5D.pdf, acesso em 01 de junho de 2016.

REBIÈRE. Therese. Incidence of a "social vat" reform: A French Scenario. IZA Discussion Paper No 7127. January, 2013.

REIS, Marcelo dos. ICMS Ecológico como Instrumento de Proteção Ambiental. Disertação de Mestrado apresentado ao Programa de Mestrado em Direito da Universidade de Marília. Marília/SP. 2011. Pag. 109.

TORRES, Heleno Taveira. DESENVOLVIMENTO, MEIO AMBIENTE E EXTRAFISCALIDADE NO BRASIL. DA EXTRAFISCALIDADE. Coordenação: Manuel Pires. Editora: Universidade Lusíada Editora. Lisboa. 2011.

VASQUES, Sérgio. O princípio da equivalência como critério de igualdade tributária / Sérgio Vasques. Coimbra : Almedina, 2008. 785 p. ; $24 \mathrm{~cm}$. Teses Orig. dissert. de doutor. em Ciências Jurídico-Económicas, Fac. de Direito da Univ. de Lisboa, 2007.

VIDONHO. Márcia Nazaré Ribeiro dos Santos. A TUTELA DO MEIO AMBIENTE ATRAVES DA APLICAÇÃO DOS PRINCIPIOS DO PROTETOR RECEBIDOR E DO NÃO POLUIDOR RECEBEDOR: A EXPERIÊNCIA BRASILEIRA DO ICMS 
AMBIENTAL. Dissertação de Mestrado apresentada como exigência final do curso de Mestrado em Ciencia Jurídico-Política da Faculdade de Direito da Universidade de Coimbra. VALADA. Rui. O IVA Social. Outubro de 2007, disponível em: http://ruivalada.blogspot.pt/2007/10/o-iva-social.html, acesso em 01 de junho de 2016. 